\title{
Pensar a universidade: um olhar a partir da extensão popular
}

\author{
Tiago Zanquêta de Souza *; Maria Waldenez de Oliveira **
}

Resumo. Este artigo é fruto de uma pesquisa de doutorado em educação, em fase de finalização, que tem como prática social a Extensão Popular em Educação Ambiental, desenvolvida por um grupo extensionista formado por sete pessoas, sendo seis estudantes do curso de Engenharia Ambiental, de uma universidade privada de Minas Gerais e pelo pesquisador, professor do mesmo curso. O referencial teórico, nesse artigo, está atrelado ao da Educação Popular e da Extensão Popular. Tem como objetivo trazer uma reflexão em torno do papel/função social da universidade, a partir da extensão popular, aqui tomada como prática social. A pesquisa que dá origem a esse artigo é qualitativa-descritiva, pois expõe as características de determinada população ou determinado fenômeno, e se vale, quanto aos meios para obtenção de dados, da pesquisa de campo. 0 registro das observações foi feito em diários de campo. Para análise dos dados, foi utilizada a análise de conteúdo, em que os documentos analisados foram os diários de campo. Esse artigo está estruturando da seguinte maneira: além das considerações introdutórias, em torno do que será discutido, traz-se uma breve descrição histórica da extensão universitária no Brasil, seguida de reflexões sobre o equívoco gnosiológico quanto ao termo extensão; quanto à extensão popular como prática social; e, por último, quanto ao papel/ função social da universidade, a partir da extensão popular.

Palavras-chave: prática social; extensão popular; educação popular.

\section{PENSAR LA UNIVERSIDAD: UNA MIRADA DESDE LA EXTENSIÓN POPULAR}

Resumen. Este artículo es fruto de un proyecto de investigación doctoral en educación, en fase de finalización, que tiene como práctica social la Extensión Popular en Educación Ambiental, desarrollada por un grupo extensionista constituido por siete personas, seis de ellos estudiantes del curso de Ingeniería Ambiental de una universidad privada de Minas Gerais y por el investigador, profesor del mismo curso. El referencial teórico, de este artículo, está vinculado al de la Educación Popular y de la Extensión Popular. Tiene como objetivo aportar una reflexión en torno al papel / función social de la universidad desde la extensión popular, aquí abordada como práctica social. El método de la investigación que da origen a este artículo es descriptivo cualitativo, ya que expone las características de una población o fenómeno en concreto en cuanto a los medios para la obtención de datos de la investigación de campo. En el análisis de los datos se ha utilizado el análisis de contenido de los cuadernos diarios de

\footnotetext{
* Universidade de Uberaba (UNIUBE), Brasil.

** Universidade Federal de São Carlos (UFSCar), Brasil.
} 
campo. La estructura que se ha dado al artículo es la siguiente: además de las consideraciones introductorias, en torno a lo que será discutido, se describe de manera breve la historia de la extensión universitaria en Brasil, acompañada de reflexiones sobre el equívoco gnoseológico en cuanto al término extensión; en cuanto a la extensión popular como práctica social; y, por último, en cuanto al papel/función social de la universidad, desde la extensión popular.

Palavras clave: práctica social; extensión popular; educación popular.

THINKING THE UNIVERSITY: A LOOK FROM THE POPULAR EXTENSION

Abstract. This article is the result of a doctoral research in education, in the final phase, which has as social practice the Popular Extension in Environmental Education, developed by an extensionist group formed by seven people, six students of Environmental Engineering course, one private university of Minas Gerais/Brazil and the researcher, teacher of the same course. The theoretical reference, in this article, is linked to that of Popular Education and Popular Extension. It aims to bring a reflection around the role / social function of the university, from the popular extension, here taken as social practice. The research that gives rise to this article is qualitative-descriptive, because it exposes the characteristics of a certain population or a certain phenomenon, and it is worth, as far as the means to obtain data, of field research. The observations were recorded in field journals. To analyze the data, the content analysis was used, in which the documents analyzed were the field diaries. This article is structured as follows: besides the introductory considerations, around what will be discussed, a brief historical description of the university extension in Brazil is presented, followed by reflections on the gnosiological misconception about the term extension; popular extension as social practice; and, finally, on the role / social function of the university, from the popular extension. Keywords: Social Practice. Popular Extension. Popular Education.

\section{INTRODUÇÃ̃o}

Este artigo é fruto de uma pesquisa de doutorado em educação em fase de finalização, que tem como tema a extensão popular desenvolvida por um grupo de extensionistas estudantes de engenharia ambiental de uma universidade privada de Minas Gerais. Esse grupo extensionista tem como bojo teórico o referencial da educação popular e da educação ambiental crítica. Esse grupo está inserido, a quase dois anos, junto a moradoras/es de dois bairros periféricos da cidade de Uberaba/MG/Brasil, que frequentam, conjuntamente, uma casa espírita que atende a esses dois bairros. Juntos, as/os extensionistas e as/os moradores constituem uma comunidade de trabalho, uma vez que 
neste caso, tem uma amplitude que permite transitar do espaço acadêmico à sociedade e desta àquele, reconhecidos cada um deles como legítimo em suas diferenças, especificidades, funções. [...] Contém, ela, a visão de mundo que cada um de seus participantes herdou das comunidades de origem, presente em maneira própria de apreender realidades, aprender e interpretar informações, formular pontos de vista, julgamentos, de mirar situações, fatos, acontecimentos. Trata-se de pontos de vista quase nunca expressos, pois dificilmente são aceitos pela academia (Silva; AraújoOlivera, 2004, s/p.).

A pesquisa de doutorado que dá origem a esse artigo é qualitativadescritiva, e, quanto aos meios, de acordo com Vergara (2009), a pesquisa é de campo e bibliográfica. Os momentos de diálogo, de escuta e de fala, entre os diferentes integrantes da comunidade de trabalho, deram-se por meio de encontros em locais e horas marcados. Dentre as técnicas de observação existentes, optou-se, na pesquisa, pela observação direta, com o propósito de facilitar o entendimento do comportamento das pessoas que compunham a comunidade de trabalho. A coleta de dados foi feita por meio de diários/ notas de campo, que é entendida como o "relato escrito daquilo que o investigador ouve, vê, experencia e pensa no decurso da recolha e refletindo sobre os dados de um estudo qualitativo" (Bogdan; Biklen, 1994, p. 150). Na pesquisa, ainda, lançou-se mão da análise de conteúdo, conforme propõem Bardin (2006) e Triviños (1987).

A categorização, segundo Bardin (2006), pressupõe análise de dados, uma vez que, para se inferir determinada categoria mediante o que apresenta os dados coletados, é necessário que haja análise, sem desconsiderar, por isso mesmo, a subjetividade da/o pesquisadora/or. Bardin (2006) propõe quatro fases como componentes do processo de análise de conteúdo: pré-análise, codificação, categorização, análise e interpretação,

Num primeiro momento, na pré-análise, os documentos analisados foram os diários de campo. A transformação dos dados em unidades de registros deu-se a partir da convergência interpretativa dos parágrafos dos diários de campo. Cada parágrafo dos diários de campo, especialmente aqueles provenientes das transcrições dos diálogos estabelecidos e organizados nos diários, foram tomados como unidades de registro. A partir da convergência entre essas unidades, foram elaboradas as categorias iniciais, intermediárias e finais, sendo essas últimas, objeto de análise e intepretação final na tese.

A partir das análises preliminares da tese é que se pode afirmar que o importante na educação libertadora, conforme coloca Freire, é que as mulheres e homens se "sintam sujeitos de seu pensar, discutindo o seu pensar, sua própria visão de mundo, manifestada implícita ou explicitamente, nas suas sugestões e nas de seus companheiros" (Freire, 2006, p. 141). 
A partir do que coloca Freire (2006), é possível compreender, então, que toda prática social se sustenta a partir da interação entre as pessoas, considerando o espaço/tempo e também suas intencionalidades. Os processos educativos decorrem de uma prática social. É imprescindível analisar essa prática atrelada ao seu contexto histórico, social e cultural, além de primar pelo reconhecimento, valorização das culturas e da participação cidadã, na busca incessante pela humanização do ser humano.

Desse modo, então, de acordo com Tauchen; Monteiro; Viero (2012) a extensão universitária ${ }^{1}$ pode ser tomada como prática social, uma vez que adquiriu diferentes entendimentos, práticas e concepções ao decorrer dos anos, experimentando diferentes visões que decorreram de uma diversidade de pessoas/universitárias/os. Sousa (2000, p.18) evidenciou três grupos-chaves para a compreensão da práxis da extensão brasileira: a "categoria discente, representada pelo movimento organizado; o Estado, representado pelo Ministério da Educação (MEC); e as próprias Universidades, como Instituições de Ensino Superior (IES) [...]". Das IES, representadas a partir do Fórum dos Pró-Reitores de Extensão, deliberaram-se importantes orientações para as políticas de extensão no Brasil, conforme será abordado.

Desse modo, o presente artigo tem como objetivo trazer uma re242 flexão em torno do papel/função social da universidade, a partir da extensão popular, como prática social.

\section{CAMINHOS DA EXTENSÃO NO BRASIL: BREVES REFLEX̃̃ES}

De acordo com Tauchen; Monteiro; Viero (2012), as universidades brasileiras sofreram, ao longo do tempo, influências diversas, provenientes de diferentes países e até mesmo dos diferentes estados de nosso país. Tais influências foram fundamentais para que as funções e as atividades das universidades se constituíssem, também, no que se conhece hoje, tanto é que, Anísio Teixeira (1998) afirmou que, no Brasil, o Ensino de $3^{\circ}$ grau sempre experenciou ações e estruturações copiadas ou ecoadas de universidades que existiam em tempos diferentes.

Até a Independência, a nossa universidade era a de Coimbra e esta vinha de suas origens medievais e refletia Bolonha e depois Paris, e com os jesuítas voltou a ser o claustro de formação do clero, deste modo, estendendo-se por

${ }^{1}$ A extensão universitária é abordada, tanto na tese quanto nesse artigo para que se entenda sua historicidade e política, até chegar à concepção de extensão popular, aqui tomada como prática social. 
todo o longo período colonial. (...) De qualquer modo, porém, mantivemos a universidade como um conjunto de escolas profissionais independentes entre si, lembrando, embora de longe, a Universidade de Paris, com vestígios germânicos nas escolas de medicina a respeito de vagas ideias de pesquisa (Teixeira, 1998, p. 70-71)

O ensino superior chegou ao Brasil tardiamente em virtude do processo de colonização portuguesa, espanhola, francesa, holandesa, enfim, europeia, que também se estendeu por toda América Latina, como coloca Florestan Fernandes (2015). Por isso, a formação profissional que se deu estava intimamente associada às estruturas europeias de universidades que existiam à época. Ainda de acordo com Tauchen; Monteiro; Viero (2012), o pesquisador e educador Álvaro Vieira Pinto (1986), em seu livro “A questão da universidade", mostra que no Brasil, sob um intenso período de dominação/ colonização europeia imperialista, "a universidade era o principal instrumento de alienação cultural” (p.10), pois, segundo essas autoras, citando Vieira Pinto (1986), a academia tinha no desempenho de suas funções, como intenção única, multiplicar as gerações componentes das classes econômica e culturalmente dominantes.

Assim, no Brasil, o ensino constituiu-se como base para a instituição encarregada de transmitir o conhecimento profissional e cultural socialmente válido. Contudo, à medida que preservava sua hegemonia institucional, fundada no conhecimento, emergiam demandas da sociedade industrial. A necessidade de novos conhecimentos científicos e tecnológicos, assim como novos ideais de universidade, balizou a inserção da pesquisa como mais uma atividade universitária (Tauchen; Monteiro; Viero, 2012, p.11).

Para Cruz (2011), as Universidades, historicamente, mesmo carregando importância particular para o desenvolvimento social a partir de inovações científicas, solidificaram a ideia de que são redentoras da sociedade e detentoras dos únicos saberes imprescindíveis para o trabalho em sociedade.

Era (e ainda é) um privilégio formar-se em uma Universidade. Seu título acadêmico era (e ainda é) garantia de boa posição social. Todavia, nem todas as pessoas tinham oportunidade de chegar à Universidade. Aqueles setores mais abalados socialmente, com pouco acesso à educação e às realizações de cidadania, ficam distantes da produção de conhecimentos e subjetividades cultivadas no seio das Universidades. Por tudo isso é que afirmamos ser a Universidade, ao longo dos tempos, mais um dos instrumentos dos grupos dominantes para legitimar a distribuição desigual de oportunidades e direitos sociais (Cruz, 2007, p.42).

Como colocado anteriormente, Sousa (2000) agrupou as práticas extensionistas em três grupos-chave. Mesquita Filho (1997) anunciava, anteriormente a Sousa (200), a existência de cinco práticas de extensão, e não apenas três, quais seriam: 1) prestação de serviços; 2) complemento ao 
conhecimento já acessível pelas atividades de ensino formal; 3) curso; 4) "remédio" (como compensação à má qualidade do ensino) e; 5) instrumento político-social.

Para Tauchen; Monteiro; Viero, (2012, p.12)

independente do modo como é realizada, existe certo consenso de que a extensão universitária deve proporcionar a articulação entre a formação acadêmica, o conhecimento produzido neste espaço e a sociedade, a fim de intervir e contribuir com as mudanças sociais.

Botomé (1996) destaca duas vertentes fundamentais de execução da extensão: uma culturalista e outra, utilitarista. Para esse mesmo autor (1996, p. 53), a universidade americana tinha como tradição na extensão, sua realização em "[...] função do desenvolvimento de comunidades, através de cursos, conferências e outras atividades variadas, criando áreas de atuação fora da sede central e desenvolvendo um processo de regionalização das universidades". Segundo Sousa (2000), na América Latina, a extensão universitária aparece ligada ao Movimento de Córdoba, em 1918, por meio dos movimentos sociais, com o objetivo de divulgar a cultura para as camadas populares da sociedade.

Tauchen; Monteiro; Viero, (2012) colocam que os princípios desse movimento extensionista, no Brasil, começam a se destacar a partir de 1938, a partir da criação da União Nacional dos Estudantes - UNE.

De modo geral, no Brasil, essas vertentes vão combinar-se para compor atividades variadas e de "nuanças múltiplas", denominadas de extensão universitária. Esta "nova atividade", inserida na Educação Superior, adquiriu contorno legal com o Estatuto das Universidades Brasileiras, de 1931. Por meio da extensão, a sociedade receberia os benefícios do trabalho universitário, redimindo a universidade elitista do isolamento e do descompromisso para com a sociedade. 0 Estatuto das Universidades Brasileiras expressa que os cursos de extensão, serão "destinados a prolongar, em benefício coletivo, a atividade técnica e cientifica dos institutos universitários" (Art. 35), voltando-se, principalmente, "à difusão de conhecimento úteis à vida individual ou coletiva, à solução de problemas sociais ou à propagação de ideias e princípios que salvaguardem os altos interesses nacionais" (Art. 42). Observa-se que as atividades de extensão, conforme o Estatuto, deveriam ser aprovadas pelo Conselho Universitário (Tauchen; Monteiro; Viero, 2012, p.13). 
De acordo com Botomé (1996, p. 60), "por via legal, instalava-se uma concepção de extensão universitária, definida por interesses do governo (divulgar conhecimentos, realizar cursos e conferências, etc.)". A partir disso, consta-se a tentativa de institucionalizar a extensão, embora como uma via de "mão única".

Desse modo, como pode-se observar, a universidade conseguiu ampliar as relações que estabelecia com a sociedade brasileira, mas não assegurou de modo efetivo essas relações. Existia a expectativa de fortalecimento de seu compromisso social, e, por isso, incluiu-se, para além da pesquisa, a extensão como via para a sedimentação dessas relações. É nessa perspectiva que Boaventura de Sousa Santos (2011), afirma que a universidade moderna, e não menos, a contemporânea, constituiu-se e ainda se constitui fundada em bases de conhecimentos científicos especializados e marcados fragmentação. Desse modo, seu poder hegemônico começou um processo de intensa degradação, o que vai justificar, então, os questionamentos quanto às relações entre o conhecimento científico pela academia produzido, e o conhecimento popular, até então menosprezado.

\section{O EQUÍVOCO GNOSIOLÓGICO, A EXTENSÃO POPULAR E $O$ PAPEL/FUNÇÃO SOCIAL DA UNIVERSIDADE}

Segundo Boaventura de Sousa Santos (20011, p. 40), "a universidade produz conhecimento que a sociedade aplica ou não, uma alternativa que, por mais relevante socialmente, é indiferente ou irrelevante para o conhecimento produzido". Ainda de acordo com esse autor, o conhecimento que se produziu nas universidades ou em instituições separadas destas, entendido como conhecimento científico, foi, por todo século XX, fragmentado e profundamente disciplinar, cuja autonomia acabou por impor um processo de produção, em certa medida, descontextualizado em relação ao status quo social.

Dessa maneira, Boaventura de Sousa Santos (2011, p.29-30) afirma que, para que a situação de descontextualização seja revertida, faz-se necessário um conhecimento pluriversitário, que é um

conhecimento contextual na medida em que o princípio organizador da sua produção é a aplicação que Ihe pode ser dada. Como essa aplicação ocorre extra-muros, a iniciativa da formulação dos problemas que se pretende resolver e a determinação dos critérios da relevância destes é o resultado 
de uma partilha entre pesquisadores e utilizadores². É um conhecimento transdisciplinar que, pela sua própria contextualização, obriga a um diálogo ou confronto com outros tipos de conhecimento, o que torna internamente mais heterogênio e mais adequado a ser produzido em sistemas abertos menos perenes e de organização menos rígida e hierárquica.

Por isso, um dos grandes desafios da universidade passa pela disposição de refletir sobre o conhecimento que produz e socializa, bem como as finalidades de suas atividades-meio, como considera Botomé (1996), uma vez que esse autor pensa o ensino, a pesquisa e a extensão como atividadesmeio da universidade, pois é por meio destas que a universidade persegue e realiza suas finalidades. Ele coloca a extensão como elo entre a pesquisa e o ensino, e disso decorre a necessidade da produção de um conhecimento contextualizado. Para Botomé (1996), ensino e pesquisa, com extensão, vão representar a produção de conhecimento coletivo, a partir da realidade. Essa realidade diagnosticada e pensada junto, permite a intervenção, de modo a resolver, solucionar, minimizar os problemas enfrentados, de forma que, na prática, se possa trabalhar por suas soluções.

Duarte (2004) considera as atividades-meio, defendidas por Botomé (1996) como minimalistas, pois a extensão, nessa perspectiva, seria apenas uma forma de exercício do ensino e da pesquisa e não outra função da universidade, o que pode restringir o posicionamento da extensão universitária como atividade fim. Almeida e Oliva (2004, p.27) ressaltam que esse olhar anuncia o elo, "mas despreza a independência funcional da extensão, isto é, o fato de cada um existir por si só, tornando urgente a sua consolidação como atividade fim, capaz de ter meios próprios para o fomento de suas atividades".

Adequadamente desenvolvida, a extensão promove o crescimento, a transdisciplinaridade e a qualidade das atividades do ensino e da pesquisa, deixando de ser vista como um atendimento tópico e assistencialista de mera prestação de serviços à comunidade. Vem a ser, principalmente, a fonte inspiradora de novos temas para investigação e, como metodologia, articula a teoria e a prática do ensino, configurando novos espaços educativos que complementam a sala de aula e o laboratório (Almeida; Oliva, 2004, p.28).

${ }^{2} \mathrm{O}$ autor considera como utilizadores, as pessoas que recebem (passivamente) a extensão. Nessa pesquisa, verificar-se-á um pouco mais adiante, que, numa comunidade de trabalho, em extensão, a produção de conhecimentos é coletiva, contextualizada, em que não se hierarquiza conhecimentos e/ou sujeitos. Trata-se de um momento/espaço de construção do conhecimento, em que todos são sujeitos, dotados de historicidade e construtores de sua própria história. É como afirma Paulo Freire (2015), nas palavras registradas na capa do livro Extensão ou Comunicação: "Conhecer é tarefa de sujeitos, não de objetos. E é como sujeito, e somente enquanto sujeito, que o homem [e a mulher] pode realmente conhecer". 
Boaventura de Sousa Santos (2011) elucida que o conhecimento contextualizado tem como princípio organizador, os diferentes contextos, linguagens as finalidades sociais que Ihe podem ser dadas. Dessa forma, 0 diálogo, como coloca Paulo Freire (2008), e a interação com outros tipos de conhecimento, que não apenas o científico, como coloca Serrano (2011), em um campo aberto, menos perene, fragmentado e hierárquico, se faz necessário, pois, uma vez que esse conhecimento se entremeia aos diferentes meandros sociais, ocorre, naturalmente, a queda das relações unilaterais que ainda dão sustentação à universidade, o que pode permitir a interatividade, os confrontos, a comunicação (Freire, 2011), o diálogo dos saberes (Leff, 2010) em uma visão de mundo coletivamente construída, sem a qual, ainda segundo Santos (2011), não ocorrerá a reinvenção da universidade.

Conforme analisa Freire (2015, p. 26),

na medida em que, no termo extensão, está implícita a ação de levar, de transferir, de entregar, de depositar algo em alguém, ressalta, nele, uma conotação indiscutivelmente mecanicista. Mas, como este algo que está sendo levado, transmitido, transferido (para ser, em última instância, depositado em alguém - que são os camponeses) é um conjunto de procedimentos técnicos, que implicam em conhecimento, que são conhecimento, se impõem as perguntas: será o ato de conhecer aquele através do qual um sujeito, transformado em objeto, recebe pacientemente um conteúdo de outro? Pode este conteúdo, que é conhecimento de ser "tratado" como se fosse algo estático? Estará ou não submetendo o conhecimento a condicionamentos histórico-sociológicos? Se a pura tomada de consciência das coisas não se constitui ainda um "saber cabal", já que pertence à esfera da mera opinião (doxa), como enfrentar a superação desta esfera por aquela em que as coisas são desveladas e se atinge a razão das mesmas?

Paulo Freire (2015) discute o equívoco gnosiológico da extensão, pois uma vez que do conceito depreende-se dinamicidade, o que de prático existe é a ação de estender (em si mesmo) um conteúdo estático. Dessa forma, aquele que estende o conteúdo, é ativo, e aquele que recebe, é "espectador", depositário, passivo. Essa seria uma visão reducionista da extensão. Freire (2015) ressalta que o ser humano é capaz de conhecer a realidade a partir de suas relações com o mundo, e, por isso, se faz necessário superar a compreensão ingênua que se tem hoje sobre a forma de construção de um conhecimento não legitimado como científico, mas que tem tanta cientificidade como aquele produzido pela academia. Essa ingenuidade, segundo o autor, se reflete em situações educativas em que o conhecimento do mundo e das coisas do mundo é tomado como um ente que pode e deve ser transferido e depositado em alguém. Nisso reside a estatização, a verbalização, e a compreensão de um conhecimento que desconhece o confronto com o 
mundo como mola propulsora e fonte verdadeira de conhecimento, nas suas inúmeras fases e níveis, não só entre homens e mulheres, mas também entre todos os seres vivos.

O conhecimento (...) exige uma presença curiosa do sujeito em face do mundo. Requer sua ação transformadora sobre a realidade. Demanda uma busca constante. Implica em invenção e em reinvenção. Reclama a reflexão crítica de cada um sobre o ato mesmo de conhecer, pelo qual se reconhece conhecendo e, ao reconhecer-se assim, percebe o "como" de seu conhecer e os condicionamentos a que está submetido seu ato (Freire, 2015, p. 28-29).

Por meio dessas colocações, percebe-se o quanto a extensão nasce atrelada a um movimento de sobreposição da universidade sobre a sociedade, no sentido de dominação da cultura, do fazer educação a partir da cultura. Freire (2015, p. 25) afirma que a expressão "extensão educativa" "só ganha sentido se encarar a educação como prática da "domesticação'". Educar e educar-se, como prática da liberdade, não é estender algo desde a "sede do saber" até a "sede da ignorância" para "salvar", com esse saber, os que dela fazem parte. Por isso, ele propõe a comunicação no lugar da extensão, pois a teoria implícita na extensão, na ação de estender algo a alguém, é uma teoria antidialógica e incompatível com a educação que acreditamos.

Freire (2015) entende que algo que é transmitido e não construído pelos partícipes da ação, expressa a superioridade de quem estende, que escolhe o que e como transmitir, desconsiderando, muitas vezes, a visão de mundo dos que vão receber a ação extensionista.

A partir de 1931, a extensão ganhou fôlego nas universidades brasileiras, mas ainda que existia a valorização do conhecimento técnico, conforme coloca Botomé (1996). Assim, a população permanecia às margens das atividades extensionistas, ou seja, ocupavam simplesmente o papel de depositários, tão criticados por Freire (2015).

As atividades (cursos e conferências) que deveriam "levar o conhecimento à sociedade" eram, e parecem permanecer assim até hoje, realizadas a partir dos interesses dos acadêmicos ou de suas ocupações predominantes e de acordo com esses interesses e ocupações (Botomé, 1996, p. 62) ${ }^{3}$. .

3 Botomé fez a afirmação em 1996, e, à frente, apresentamos os avanços e estagnações com relação à prática da extensão, nos dias atuais. Lembramos que essa retomada histórica se dará a partir de uma análise em torno, especialmente, da reforma universitária que ocorreu na década de 60, e que vai dar ao Brasil um outro fôlego para a prática extensionista. 
Nota-se, até então, que a extensão foi abordada na perspectiva do equívoco gnosiológico apontado por Freire (2015), muito embora também pareça como uma tentativa de correção da ausência de comunicação e de intervenção da universidade, na sociedade. Desse modo, desenvolveu-se a extensão como curso, com vias à divulgação e produção técnico-científica da academia, não superando a mera prestação de serviços sociais, na posição daqueles que "salvam"; não atravessou para além da promoção de eventos e de atividades filantrópicas, por meio da execução plena de comunicação com a sociedade. A extensão ainda se configurava como complemento às atividades de ensino e de pesquisa, que levava até à população, saberes e ações que seriam restritas ao espaço universitário e como instrumento político-social, de imposição e de opressão.

Na análise de Botomé (1996, p. 62),

os cursos assim chamados poderiam ter sido um excelente instrumento para fazer com que toda a sociedade tivesse mais acesso ao conhecimento disponível, mas sua formulação, contaminada pelas práticas já existentes e pelas concepções sobre ensino predominantes, não produziram alterações significativas no papel social da Universidade Brasileira.

Ou seja, para Botomé (1996), as atividades que se consideravam como extensão eram mais do mesmo, ou seja, na prática, não era nada além do que já se fazia. Considera o autor que as atividades de extensão, principalmente os cursos, eram/são apenas mais uma atividade de ensino muito próxima ao que anteriormente existia.

No final dos anos cinquenta e início dos anos sessenta, do século XX, surgiram

as exigências para se efetivar o compromisso social da universidade e uma nova função para a extensão: além de redentora social, como atividades capazes de redimir o ensino e a pesquisa universitários do descompromisso e do distanciamento dos problemas sociais. No entanto, do ponto de vista legal, a Lei n. 4.024/61 reforça a extensão como uma modalidade de curso, como mais uma possibilidade de atividade universitária (Tauchen; Monteiro; Viero, 2012, p.16).

Ainda de acordo com essas autoras, a partir da lei de reforma universitária (Lei n. 5.540/68), a extensão passou a ser compulsória, com a tentativa de promover o fortalecimento cívico e comunitário, que seria complementado com a inserção de disciplinas dessa natureza. 
Para Botomé (1996, p.63),

O compromisso social da Universidade precisa ser realizado por todas as atividades da instituição e não apenas considerar uma delas como sendo aquela que o realiza, enquanto as demais, que não o fazem, justificam a existência e "papel privilegiado" daquela que o "realiza".

Dessa forma, a universidade precisaria repensar o papel do ensino e da pesquisa, se têm por compromisso, a transformação e a solução daquilo que se entende, junto à população, como problema social. Seria preciso repensar também a educação que se faz, como prática social, com vias à produção científica concernente às demandas sociais, e não distante delas.

De acordo ainda com Tauchen; Monteiro; Viero, (2012), foi a partir de 1987, por meio da criação do Fórum de Pró-Reitores de Extensão das Universidades Públicas Brasileiras (FORPROEX), que se rediscutiu a função social da universidade, a institucionalização, o financiamento e as políticas de extensão por parte do Estado. O FORPROEX definiu a extensão como

[...] processo educativo, cultural e científico que articula o Ensino e a Pesquisa de forma indissociável e viabiliza a relação transformadora entre Universidade e Sociedade. A Extensão é uma via de mão-dupla, com trânsito assegurado à comunidade acadêmica, que encontrará, na sociedade, a oportunidade de elaboração da práxis de um conhecimento acadêmico. No retorno à Universidade, docentes e discentes trarão um aprendizado que, submetido à reflexão teórica, será acrescido àquele conhecimento (2001, p.05).

Entende-se que esta interação entre os saberes acadêmicos e populares, conforme aponta Serrano (2011) e Melo Neto (2005), vai fortalecer a universidade e a sociedade, mas, ainda assim, a extensão ainda não era considerada como atividade de articulação, entremeando o ensino e a pesquisa. Botomé (1996) questiona essa visão dos Pró-reitores que participaram do FORPROEX, principalmente pelo fato de que não é possível dissociar ensino-pesquisa-extensão.

Ensino e pesquisa são indissociáveis em virtude dos processos envolvidos, pela recursividade e pela ação dos sujeitos que os acompanham, mas a extensão não é o agente dessa articulação. 0 ensino e a pesquisa precisam contemplar certas características (contextualização, problematização do conhecimento, aprendizagem reconstrutiva, entre outras) para que essa articulação aconteça por meio das atividades de alunos e de professores. Em outras palavras, não é porque fazemos extensão que garantimos a articulação entre ensino e pesquisa e a "relação transformadora entre a universidade e a sociedade" (Tauchen; Monteiro; Viero, 2012, p.16). 
De acordo com Cruz (2011), a extensão, sendo um dos pilares que constitui a Universidade, vai sofrer as influências históricas e políticas apresentadas. A extensão universitária, embora seja institucionalmente concebida como um "processo educativo, cultural e científico, que articula o ensino e a pesquisa de forma indissociável e viabiliza a relação transformadora entre a Universidade e a Sociedade" (FORPROEX, 2007, apud Cruz, 2011, p.41) permanece associada a dimensões assistencialistas e mercadológicas, pois muitas ações de extensão se dedicam, especialmente, à prestação de serviços e trabalhos para a comunidade, por existir caminhos e exigências procedimentais, técnicas, dos quais é difícil o popular participar. "Em muitos casos, trata-se de ultraespecializações, necessárias para a vida em sociedade, e que podem estar à disposição das classes populares, o que não supõe, imediatamente, autoritarismo ou assistencialismo" (CRUZ, 2011, p.45), principalmente se essas ações não substituírem o estado ou alienando a participação das pessoas da comunidade na cobrança de seus direitos socialmente conquistados.

De acordo com Rosa (2011) hoje existe duas formas de entendimento e compreensão do papel da extensão universitária: uma como uma via de mão única, também estudada por Botomé (1996), na qual a universidade, ou seja, a academia, prestaria um serviço à sociedade; e a outra como via de mão dupla, em que se estabelece a partilha de conhecimentos e saberes populares e acadêmicos, desprezando ainda a pluralidade dessa relação existente. Uma terceira vertente, mais atual, vai na contramão dessas duas anteriores, ao propor que a extensão universitária se configure como alternativa para a construção plural das relações entre a academia e as classes populares, uma vez que permite repensar a relação entre a construção do conhecimento e suas finalidades sociais, ou seja, pensar no como é produzido e a quem serve.

Trata-se então, de propor e pensar a extensão popular, uma vez que é "mediada por sujeitos comprometidos com as transformações sociais e implicados na conquista de uma formação universitária e uma produção de conhecimentos mais próximos aos setores populares" (ROSA, 2011, p.49).

De acordo com Cruz (2011, p.41)

Apesar de constituir uma ação desenvolvida há décadas por setores acadêmicos em parceria com os movimentos populares, a denominação Extensão Popular somente veio a ser consolidada há poucos anos. E, ao contrário do que pode parecer, não é apenas uma nova configuração ou qualificação para a extensão ou outro "jeito de fazer" extensão universitária, mas uma perspectiva teórica e um recorte epistemológico da extensão, que traz não apenas metodologias, mas intencionalidades distintas para esse campo acadêmico. 
De acordo com Cruz (2011), é dentro da Universidade que surgem diversas experiências desenvolvidas para as classes populares e, com elas, a horizontalização na relação entre o científico e o popular.

A extensão popular alimenta-se da crítica para o exercício de ações educativas. Nesse sentido, tem papel determinante, pois além de superação do "senso comum", também é propositiva. A extensão popular assume um ideário transformador, constituindo uma dimensão que vai além de um trabalho simples. Assumindo a crítica como pressuposto, envolvendo os setores populares e desenvolvendo atividades coletivas, a extensão popular, na área rural ou na área urbana, adquire a dimensão metodológica exposta, podendo ser caracterizada como trabalho social útil. Isso possibilita um avanço para além de vários receituários sobre a extensão, superando, por exemplo, as perspectivas de "mão única" e "mão dupla". Extensão como trabalho social é criadora de produtos culturais. Tem origem na realidade humana e abre possibilidade de se criar um mundo, também, mais humano. É o trabalho social que transforma a natureza, criando cultura. Um trabalho social e útil, com explícita intencionalidade de transformação (Melo Neto, 2005, s/p).

Dessa forma, nesse artigo, toma-se a extensão popular como prática social, uma vez que se sustenta a partir da interação entre as pessoas, considerando o espaço/tempo e também suas intencionalidades.

Os estudos em práticas sociais e processos educativos apontam para a necessidade de compreender "como e para que as pessoas se educam [...] em situações escolarizadas ou não, assim como o de apreender a influência desses processos nas aprendizagens escolares" (Oliveira et al., 2009, p.1). Contribuem também para o desenvolvimento de um olhar especial para os espaços escolares, com o objetivo de perceber, entender e identificar como as pessoas constroem seu aprendizado, lutam por transformações sociais e se educam, na escola. Nessa perspectiva, os processos educativos são "inerentes e decorrentes de práticas sociais" (Oliveira et al., 2009, p.1).

As pessoas atribuem sentido e significado ao mundo em que vivem, uma vez que se situam em espaços e realidades que Ihes são peculiares. Essa forma de ver e entender o mundo permite também que nele se intervenha, e por meio das práticas sociais essas intervenções tornam-se fecundas e evidentes (Cota, 2000, p.211).

A construção do sujeito como pessoa dá-se na convivência com outras pessoas, ou seja, na coletividade, e a construção dessa coletividade se dá, também, a partir da presença desse e de outros sujeitos. Não existe, então, um sujeito singularizado na prática social, mas sujeitos que juntos estão com um ou mais objetivos em comum. Vale lembrar, no entanto, que a prática social pode ou não ser educativa (Oliveira, et al., 2009). 
A participação do sujeito no processo de construção do conhecimento não é algo mais democrático, mas algo mais eficaz.

É por isso que uma coisa é viver a cotidianidade no contexto da origem, imerso nas tramas habituais de que facilmente podemos emergir para indagar, e outra é viver a cotidianidade no contexto do empréstimo que exige de nós não só fazermos possível que a ele nos afeiçoemos, mas também que o tomemos como objeto de nossa reflexão crítica, muito mais do que o fazemos no nosso (Freire, 2008, p.48).

Assim, quando os seres conscientes querem, refletem e agem para derrubar as "situações-limite" que os e as deixaram a si e a quase todos e todas limitados a ser-menos o "inédito-viável" 4 não é mais ele mesmo, mas a concretização dele no que ele tinha antes de inviável realizando o sonho. Ao conviver em práticas sociais, as pessoas começam a entender não há a predominância do definitivo, do pronto e do acabado, e, por meio de diferentes processos educativos consolidados, alcançam o reconhecimento do inacabamento.

Por meio de suas experiências, os seres humanos vão elaborando modos de viver, posturas, condutas, saberes e valores que são empregados como recursos para interpretar e mudar a realidade percebida. Daí a importância de não só educadores e educadoras, mas de todos e todas, dizer a palavra propondo a superação da opressão histórica, pois só assim se construirá o caminho para a transformação da realidade.

De acordo com Paulo Freire (2015) essa prática deve ter, então, por princípio, o diálogo amoroso, que direciona para o humanismo verdadeiro, no exercício dialógico, desprovido da tentativa de invasão, de manipulação, e também, sempre empenhado na transformação constante da realidade.

O que se pretende com o diálogo, em qualquer hipótese (seja em torno de um conhecimento científico e técnico, seja de um conhecimento "experiencial"), é a problematização do próprio conhecimento em sua indiscutível reação com a realidade concreta na qual se gera e sobre a qual se incide, para melhor compreendê-la, explica-la, transformá-la" (FREIRE, 2015, p.65).

${ }^{4}$ Algo que o sonho utópico sabe que existe mas que só será conseguido pela práxis libertadora que pode passar pela teoria da ação dialógica de Freire ou, evidentemente, porque não necessariamente só pela dele, por outra que pretenda os mesmos fins. 0 "inéditoviável" é na realidade uma coisa inédita, ainda não claramente conhecida e vivida, mas sonhada e quando se torna um "percebido destacado" pelos que pensam utopicamente, esses sabem, então, que o problema não é mais um sonho, que ele pode se tornar realidade. 
A extensão popular então, deve promover o encontro amoroso de homens e mulheres, que, mediatizados pelo mundo, o "pronunciam", o transformam, e em o transformando, o humanizam para a humanização de todos e todas (Freire, 2015).

\section{REFERÊNCIAS}

Almeida, Cleide Rita Silvério; Oliva, Vagner José (2004). A Extensão Universitária como Atividade Fim. In. Interagir: Pensando o Extensão, Rio de Janeiro, n. 5, p. 27-36, jan./jun..

Bardin, L. (2006). Análise de conteúdo. In. L. de A. Rego \& A. Pinheiro (Trads.). Lisboa: Edições 70, (Obra original publicada em 1977).

Bogdan, Roberto; Biklen, Sari (1994). Notas de Campo. In: Bogdan, Roberto; Biklen, Sari. Investigação qualitativa em educação: uma introdução à teoria e aos métodos. Porto: Porto Editora, p.150-175.

Botomé, Sílvio Paulo (1996). Pesquisa Alienada e Ensino Alienante: o equívoco da extensão universitária. Petrópolis/RJ: Vozes; São Carlos-SP: EDUFSCAR; Caxias do Sul - RS: EDUCS,.

Cota, Maria Célia (2000). De Professores e carpinteiros: encontros e desencontros entre teoria e prática na construção da prática profissional. Educação e Filosofia, v. 14, n 27/28, p. 203-222.

Cruz, Pedro José Santos Carneiro (2011). Extensão Popular: A Reinvenção da Universidade. In. Vasconcelos, Eymard Mourão; Cruz, Pedro José Santos Carneiro. (org). Educação popular na formação universitária: reflexões com base em uma experiência. São Paulo: Hucitec; João Pessoa: Editora Universitária da UFPB.

Duarte, Júlio César P. Extensão Universitária: função própria ou filosofia de ação da universidade? Disponível em <http://www.ucg.br/flastilartigos/ extensaouniversitaria.htm>. Acesso em 19 Set. 2016.

Fernandes, Florestan (2015). Poder e contrapoder na América Latina. 2.ed. São Paulo: Expressão Popular.

Freire, Paulo (2006). Pedagogia da esperança: um reencontro com a Pedagogia do Oprimido. 6.ed. Rio de Janeiro: Paz e Terra.

(2008). Pedagogia da Esperança: um reencontro com a pedagogia do oprimido. Rio de Janeiro: Paz e Terra.

(2015). Extensão ou comunicação. 17.ed. São Paulo: Paz e Terra.

Leff, Enrique. Epistemologia Ambiental. 5.ed. São Paulo: Cortez, 2010.

Melo Neto, José Francisco de (2005). Extensão popular - valores éticos para uma cultura política pela extensão universitária. In. VIII Congresso Ibero-Americano de extensão universitária. Navegar é preciso... Transformar é possível. [evento na internet]. 2005; Rio de Janeiro, Brasil. [Acesso em 02 de Nov. 2014]. 
Mesquita Filho, Alberto (1997). Integração ensino-pesquis-aextensão. Integração ensino pesquisa e extensão. [on line] vol. 3(9). Disponível na internet em http:// www. ecientificocultural.com/ECC2/artigos/epe.htm. Acesso em 19 Set. 2016.

Oliveira, Maria Waldenez de; Silva, Petronilha Beatriz Gonçalves e; Gonçalves Junior, Luiz; Garcia-Montrone, Aida Victoria; Joly, Ilza Zenker (2009). Processos educativos em práticas sociais: reflexões teóricas e metodológicas sobre pesquisa educacional em espaços sociais. $32^{a}$ Reunião Anual da ANPEd. Caxambu/MG.

Pinto, Álvaro Vieira (1986). A questão da universidade. São Paulo: Cortez: Autores Associados.

Rosa, Isaquiel Macedo da (2011). Educação popular, integralidade e formação em enfermagem no cenário da extensão universitária. [Dissertação de Mestrado]. Programa de Pósgraduação em Enfermagem, Universidade Federal do Rio Grande do Sul.

Santos, Boaventura de Sousa (2011). A universidade no século XXI: para uma reforma democrática e emancipatória da universidade. 3.ed. São Paulo: Cortez.

Serrano, Rossana Maria Souto Maior (2011). As tensões na universidade e as pretensões da extensão universitária popular. In. Baptista, Maria das Graças de Almeida; Palhano, Tânia Rodrigues. Educação, Extensão Popular e Pesquisa: metodologia e prática. João Pessoa: Editora Universitária da UFPB.

Silva, Petronilha Beatriz Gonçalves; Araujo-Olivera, Sonia Stella (2004). Cidadania, ética e diversidade: desafios para a formação em pesquisa. VI Encuentro - Corredor de las ideas del cono sur "Sociedad civil, democracia e integración" - Montevideo - 12 marzo. Salón 3 - Educación - Educación Superior.

Sousa, Ana Luiza Lima (2000). A história da extensão universitária. São Paulo: Alínea.

Tauchen, Gionara; Monteiro, Maria Cecília Madruga; Viero, Tatiane Vedoin (2012). Políticas, concepções e ações de Extensão na Educação Superior Brasileira. In. Momento, Rio Grande, 21 (1): 9-28.

Teixeira, Anísio (1998). A universidade de ontem e hoje. Rio de Janeiro: EdEURJ.

Triviños, A. (1987). Introdução à pesquisa em ciências sociais: a pesquisa qualitativa em educação. São Paulo: Atlas,.

Vergara, Sylvia C. (2009). Métodos de coleta de dados no campo. São Paulo: Atlas. 
